\title{
The Role of Cardiac Ultrasound in Stem Cell Therapy
}

\author{
Andrew M. Kahn • Anthony N. DeMaria
}

Received: 10 December 2008 / Accepted: 15 December 2008 /Published online: 22 January 2009

(C) The Author(s) 2009. This article is published with open access at Springerlink.com

\begin{abstract}
The role of cardiac ultrasound in evaluating and treating patients with stem cell therapy is reviewed. A number of ultrasound techniques can be used in the evaluation, therapy delivery, and follow-up of patients treated with stem cell therapy. These techniques include evaluation of myocardial systolic and diastolic function, perfusion, ischemia, viability, synchrony, and imaging targeted to specific cell types.
\end{abstract}

Keywords Echocardiography · Cardiac Ultrasound ·

Stem Cell Therapy · Contrast Echocardiography .

Tissue Doppler Imaging · Speckle Tracking

\section{Introduction}

Imaging serves a number of important roles in stem cell therapy for cardiac disease. In particular, imaging can be used to (1) define the presence and severity of phenotype to be treated, (2) guide the delivery of therapy, (3) follow the course of disease and evaluate the effects of therapy, (4) provide labels and define mechanisms of therapy, (5) evaluate survival and function of engrafted cells, and (6) perhaps to facilitate the process of cell therapy. Furthermore, imaging has the potential to determine the engraftment, survival, and local function of cell therapy and to

A. M. Kahn • A. N. DeMaria

University of California,

San Diego, CA, USA

\section{A. M. Kahn ( $\square)$}

Division of Cardiology, UCSD Medical Center,

Mail Code 8411, 200 W. Arbor Drive,

San Diego, CA 92103-8411, USA

e-mail: akahn@ucsd.edu identify the mechanism of benefit. In addition, while the ultimate goal of therapy is to decrease morbidity and mortality, imaging can serve as a useful surrogate endpoint, especially in preliminary trials.

An ideal imaging technique would provide threedimensional digital tomographic data, have high temporal and spatial resolution, allow molecular imaging, and would be inexpensive, portable, non-invasive, and not require radiation. It would also provide data on cardiac structure and function, coronary anatomy, coronary plaque composition, myocardial perfusion, and myocardial viability and scar anatomy. In addition, molecular imaging may provide data on appropriate cellular and intracellular targets. Ultrasound, computed tomography (CT), nuclear imaging, and magnetic resonance imaging (MRI) have all been employed in stem cell therapy trials [1]. While no single modality is ideal, each has different attributes and these modalities often can provide complimentary information. In this review, we discuss the specific roles of ultrasound in stem cell therapy, its applications, and its limitations.

Transthoracic echocardiography is a well-established technique, which can be done at the bedside, involves no radiation, and is essentially harmless. While the image quality can be variable and dependent on imaging windows, diagnostic images can be obtained in the vast majority of patients [2]. Although initial studies demonstrated that the evaluation of left ventricular (LV) structure and function was more reproducible with MRI [3], subsequent reports have indicated that the use of contrast can overcome this limitation [4]. Unlike MRI, the presence of a pacemaker or defibrillator is not a contraindication and does not significantly affect image quality. Transesophageal echocardiography is more invasive but can provide diagnostic images in patients in whom transthoracic echocardiograms may be suboptimal [5]. 


\section{Stem Cell Delivery}

Imaging is frequently used to track the delivery of stem cells to the target tissue. However, ultrasound has had a limited role in tracking cell delivery, and this has thus far been done with other modalities such as MRI and nuclear imaging. Tracking stem cells usually involves targeted imaging, usually aided by cell labeling, which must be done in a non-toxic way. Thus far, no agents have been identified to label cells for ultrasonic detection in humans.

One advantage of ultrasound is that it can be done in real time at the time of injection. Transesophageal echocardiography allows excellent real-time visualization of myocardium and can be done at the time of cardiac catheterization. This technique is often used during the closure of atrial septal defects [6] and could be similarly used to visualize myocardium at the time of stem cell injection. However, thus far, this has not been significantly employed in stem cell trials. In one recent pilot study, Bara et al. [7] used CliniMACS nanoparticles (Miltenyi Biotec, Bergisch Gladbach, Germany) to label CD133+ cells injected into porcine myocardium. The ClinicMACS nanoparticles are iron dextran beads, which are ferromagnetic, thus allowing cell separation after labeling using magnetic selection. Transesophageal echocardiography was used to image implanted cells in vivo at the time of injection and in follow-up 8 weeks later and demonstrated good visualization of the implanted cells as regions of high signal.

\section{Left Ventricular Function}

Left ventricular size and function can be quantified by measuring overall volumes, mass, and ejection fraction. In addition, regional wall thickening and endocardial motion can be qualitatively and quantitatively assessed. Quantitative assessments of left ventricular volumes and function are used in all stem cell trials. With ultrasound, left ventricular volumes are typically quantified using biplane measurements and the modified Simpson's rule. This method has been validated [8], but it is less reproducible than MRI [3]. However, the use of left ventricular contrast agents enhances endocardial definition (Fig. 1) and significantly improves the accuracy and reproducibility of volumes by ultrasound $[3,9]$.

Left ventricular diastolic filling patterns are known to have prognostic importance in patients with systolic dysfunction [10]. Ultrasound is the primary tool used to assess diastolic function and hence non-invasively estimate left ventricular filling pressures. Doppler ultrasound measurements allow assessment of mitral valve inflow and pulmonary vein flow. In addition, using different filter settings, ultrasound with Doppler can quantify myocardial tissue movement. Ultrasound of the myocardium at the mitral valve annulus, in combination with mitral valve filling data, has been shown to correlate well with pulmonary capillary wedge pressure [11].

Traditionally, while overall LV function is quantified by calculation of the ejection fraction, non-invasive evaluation of regional wall motion by echocardiography is often qualitative. However, quantitative regional systolic function is of interest, especially in assessing function at the sites where therapy is delivered. Because myocardial movement may be passive and occur due to local tethering or myocardial translation, motion may not necessarily correlate with local myocardial function. Several new ultrasound technologies have recently emerged that allow quantification of regional systolic function by measuring strain and strain rate as the change in segment length over time. Strain measures local myocardial deformation, and strain rate is the time-dependent change in strain. These quantities are not affected by tethering and can be measured via ultrasound using either tissue Doppler imaging (TDI) [12] or speckle tracking [13].

TDI removes the high frequency, low amplitude signal from blood using a low-pass filter, to measure myocardial velocities. The strain rate is equal to the spatial velocity gradient and thus can be obtained by measuring the myocardial velocity using TDI at adjacent points and then calculating the gradient [12]. The local strain, which is equal to the time integral of the strain rate, can then be calculated from the strain rate. In practice, the strain rate is obtained by calculating the average velocity gradient over a small area in which the segment of interest is parallel to the ultrasound beam, as shown in Fig. 2. These techniques have been successfully used to quantitatively measure regional left ventricular function and have been validated in animals [14] and humans [15].

TDI has the limitation that it can only measure velocities along the ultrasound beam. Speckle-tracking uses natural acoustic interference patterns to evaluate tissue movement by tracking signal inhomogeneities within the image through out the entire cardiac cycle $[13,16]$. Such signal inhomogeneities appear as scatter reflectors or speckles within the myocardial wall. Because the technique is not constrained by angle dependence, it allows for reconstruction of two-dimensional tissue dynamics in all directions and calculation of regional longitudinal, radial and circumferential strain and strain rates. This technique has been validated using MRI and sonomicrometery as references [17]. Figure 3 shows an example of speckle tracking to evaluate regional function from the apical four-chamber view in a patient with normal left ventricular function.

Real-time three-dimensional ultrasound is another emerging technology, which permits quantification of regional as well as global systolic function. This technique 
Fig. 1 Example of myocardial contrast (Definity, Bristol-Myers Squibb Medical Imaging Inc., North Billerica, Massachusetts) to improve endocardial definition. Apical four-chamber views are shown at end-diastole $(\mathbf{a}, \mathbf{b})$ and end-systole (c, d), without $(\mathbf{a}, \mathbf{c})$ and with (b, d) contrast, from a patient with a recent myocardial infarction. The apical septal hypokinesis (arrow) is more apparent in the contrastenhanced images
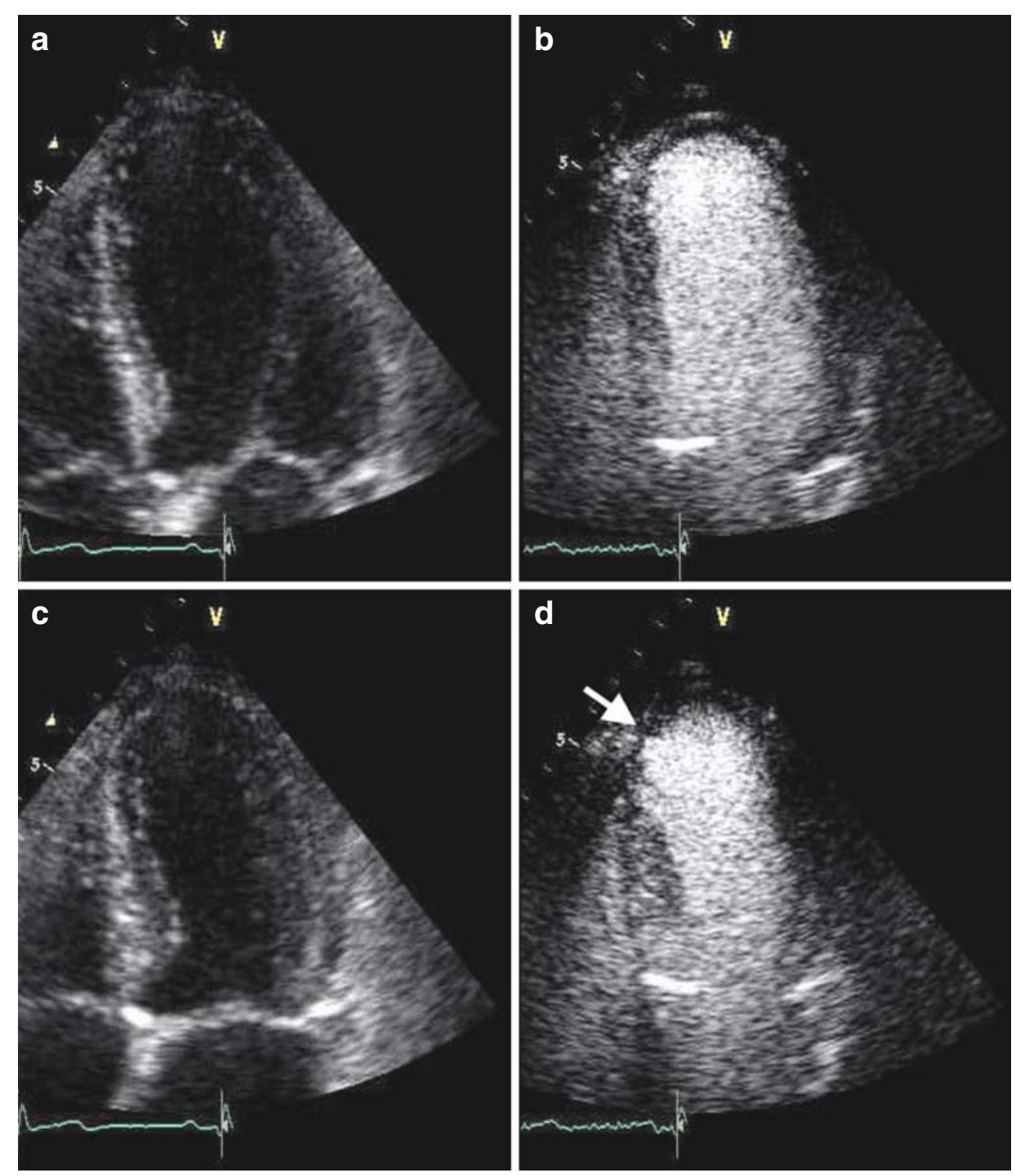

uses an ultrasound probe containing a matrix array of elements [18] yielding a three-dimensional pyramid-shaped volumetric data set. Three-dimensional echocardiography has been successfully employed in the measurement of LV function [19] and has been shown to be more reproducible than two-dimensional ultrasound [20]. In addition, using specialized post-processing software, regional ejection fraction can be calculated for each segment [19, 21], as shown in Fig. 4.

\section{Left Ventricular Dyssynchrony}

Left ventricular dyssynchrony has emerged as an important therapeutic target for treatment in subsets of patients with left ventricular systolic dysfunction. The optimal method of assessing LV dyssynchrony remains uncertain, despite significant effort evaluating different modalities and measuring techniques and algorithms. Several ultrasound algorithms have shown promising results in multiple single-center trials [22]. However, in a multicenter trial comparing different ultrasound techniques and algorithms, none of the methods tested had high sensitivity and specificity [23]. Nevertheless, ultrasound remains the most common modality used to evaluate dyssynchrony, and its assessment is a potentially useful surrogate endpoint in stem cell trials. Notably, Chang et. al. recently used ultrasound to show that stem cell therapy after acute myocardial infarction resulted in improved LV synchrony [24].

\section{Perfusion Imaging}

Although radionuclide methods are the standard technique employed, contrast echocardiography can also be applied to the imaging of myocardial perfusion. Data exist that 
Fig. 2 Example of TDI (EchoPAC, GE Healthcare) to measure longitudinal strain. Two regions of interest (ROI) are placed on the two-dimensional image acquired using color Doppler imaging. The longitudinal strain is plotted for the corresponding septal (yellow ROI and curve) and lateral (green ROI and curve) segments
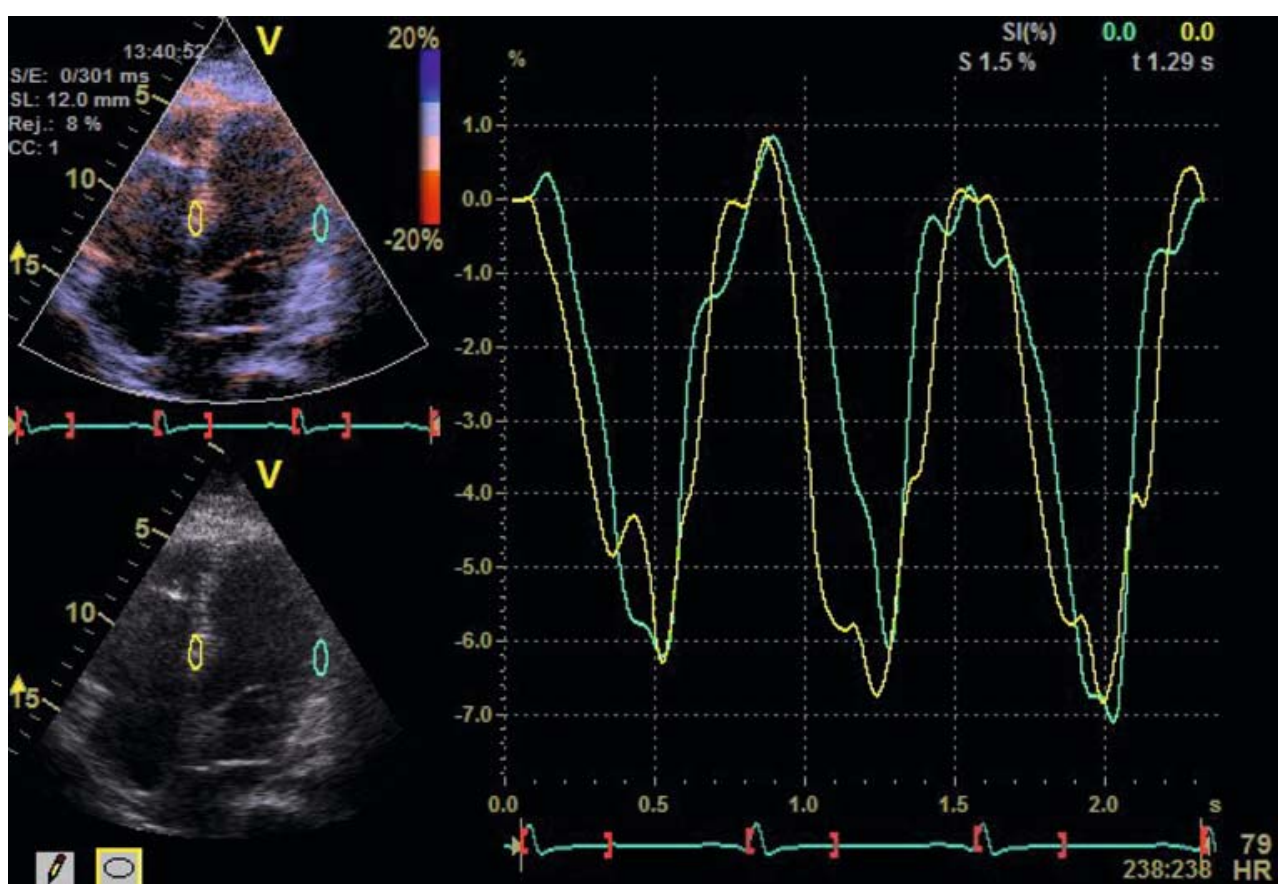

absolute myocardial blood flow can be determined using continuous infusion of a microsphere solution and subsequent imaging following destructive ultrasound pulses [25, 26]. Reduced ultrasonic signal intensity (defect) by this technique has been shown to be relatively sensitive and specific for the detection of ischemia [27] and can quantify infarct size and area at risk associated with ischemia [28]. In addition, contrast ultrasound assessment of perfusion has been shown to have additional prognostic value in patients undergoing stress testing [29]. Hence, this technique may

Fig. 3 Example of twodimensional speckle tracking (EchoPAC, GE Healthcare). The left ventricular myocardium is divided into six regions (upper left). Speckle tracking is then used to calculate regional longitudinal strain, which is then plotted vs. cardiac phase (right) and displayed as color M-Mode (lower left)

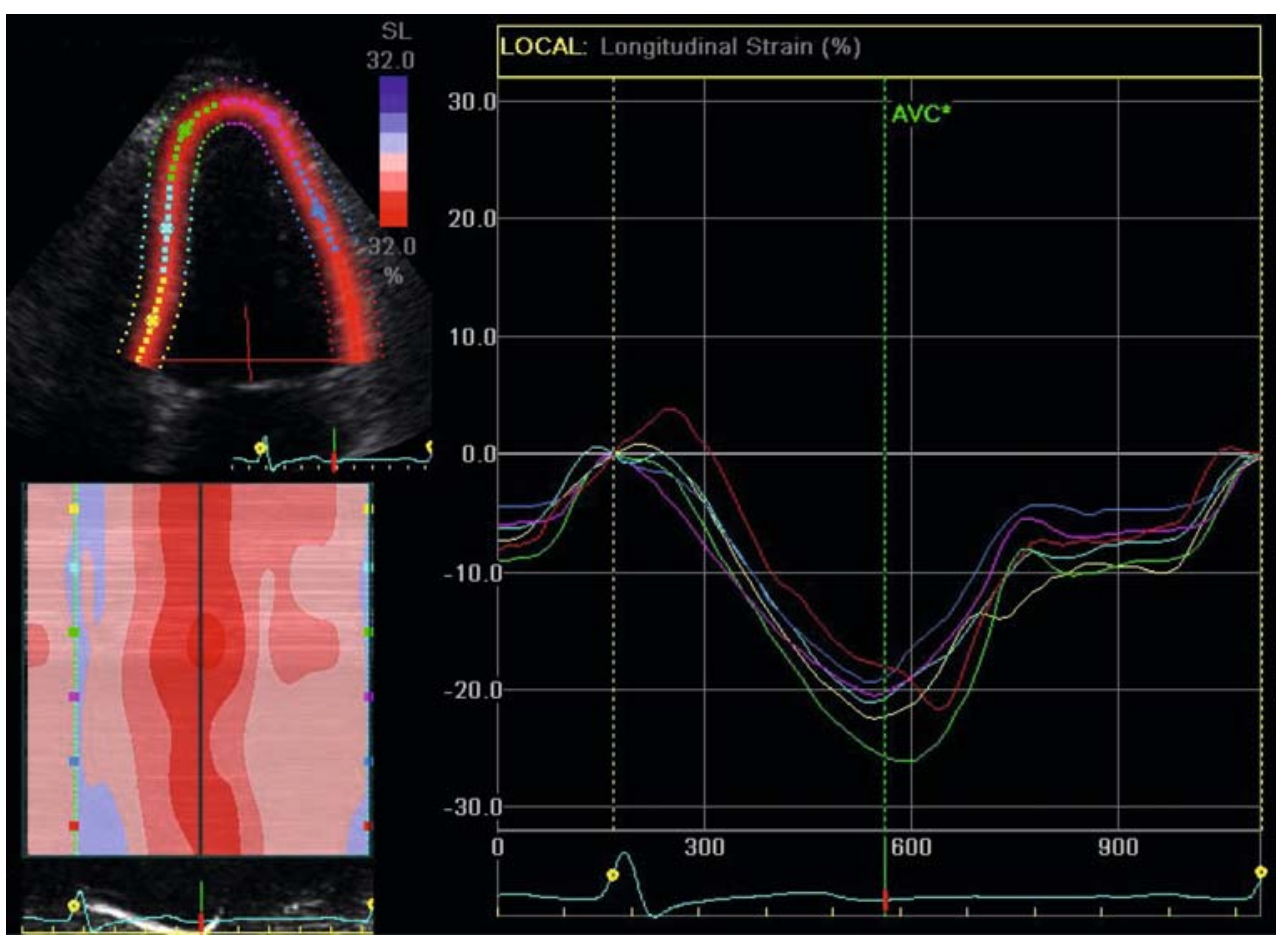

be of use in selecting patients for treatment and following the effect of stem cell therapy upon myocardial perfusion.

\section{Myocardial Viability}

Evaluation of myocardial viability is important in determining patient prognoses, stratifying patients for stem cell therapy, and choosing targets for therapy. Multiple modalities have been used to evaluate viability including MRI, 
Fig. 4 Example of threedimensional echocardiography with post-processing (4D LVAnalysis, TomTec Imaging Systems) to obtain regional wall motion from a volumetric ultrasound data set. The upper images show the calculated left ventricular volume superimposed on the grey scale images. The volumes of each of the 16 regions (map, lower left) are plotted (lower right) as a function of time during the cardiac cycle

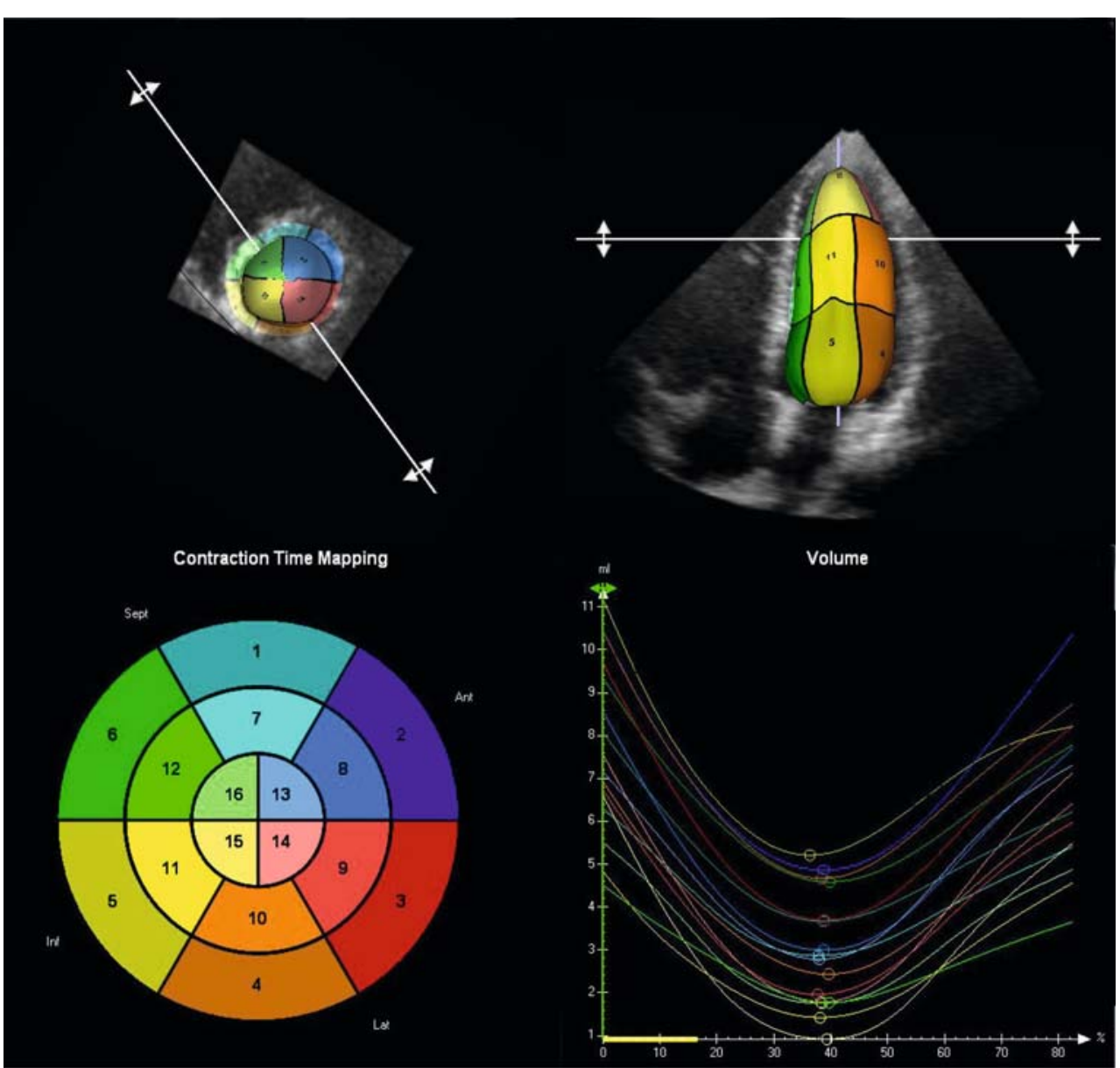

single photon emission CT, positron emission tomography, and ultrasound. Dobutamine ultrasound has been validated in multiple studies and widely used as a tool for assessing viability [30]. The classic manifestation of viability by dobutamine stress testing is the "biphasic response" whereby dyssyngeric myocardium shows enhanced contractility at low doses and then clear deterioration as ischemia appears at higher doses of the agent. Intravenous contrast agents to improve endocardial visualization have been shown to further improve the accuracy of viability assessment by ultrasound [29]. Myocardial viability can also be evaluated using contrast echocardiography to determine the transmural extent of infarction, which has been shown to agree with similar measurements by MRI [31]. The presence of at least patchy opacification of an infarcted region by contrast echo is indicative of microcirculatory integrity and thus viability, while the absence of any opacification indicates non-viable myocardium.

\section{Targeted Imaging}

Targeted imaging remains a very active area of research using different modalities to identify and image specific tissue components. These techniques have the potential to better identify appropriate myocardial regions for stem cell therapy. While targeted imaging is not yet used clinically, it has been shown to have great potential in a number of animal studies. Targeted imaging can be done with contrast ultrasound using microbubbles targeted to a number of specific markers. For example, phosphatidylserine containing lipid microbubbles have been used to target leukocytes and hence permit imaging of inflammation associated with myocardial reperfusion injury [32]. In addition, Kaufmann et. al. [33] have recently shown that ischemic myocardium can be visualized using contrast echocardiography targeted to P-selectin. It is possible that these techniques may be extended to permit targeted delivery of stem cells.

\section{Conclusion}

In this paper, we have reviewed current cardiac ultrasound technology, as it applies to treating patients with stem cell therapy. For many of the applications discussed, ultrasound is one of several different available modalities. Because it is an established technology, is portable, essentially harmless, and versatile, ultrasound remains an important part of the 
imaging armamentarium used to evaluate and treat patients with stem cell therapies.

Conflict of interest A. N. DeMaria has received research support from Angioblast Systems and CardioVascular BioTherapeutics, and has consulted for and received research support, speaker's fees, and honoraria from Acusphere, Bristol-Myers Squibb, General Electric Medical systems, Philips Medical systems, Schering, and Siemens.

Open Access This article is distributed under the terms of the Creative Commons Attribution Noncommercial License which permits any noncommercial use, distribution, and reproduction in any medium, provided the original author(s) and source are credited.

\section{References}

1. Beeres, S. L., Bengel, F. M., Bartunek, J., Atsma, D. E., Hill, J. M., Vanderheyden, M., et al. (2007). Role of imaging in cardiac stem cell therapy. Journal of the American College of Cardiology, 49(11), 1137-1148.

2. Bansal, R. C., Tajik, A. J., Seward, J. B., \& Offord, K. P. (1980). Feasibility of detailed two-dimensional echocardiographic examination in adults. Prospective study of 200 patients. Mayo Clinic Proceedings, 55(5), 291-308.

3. Grothues, F., Smith, G. C., Moon, J. C., Bellenger, N. G., Collins, P., Klein, H. U., et al. (2002). Comparison of interstudy reproducibility of cardiovascular magnetic resonance with twodimensional echocardiography in normal subjects and in patients with heart failure or left ventricular hypertrophy. The American Journal of Cardiology, 90(1), 29-34.

4. Hoffmann, R., von Bardeleben, S., ten Cate, F., Borges, A. C., Kasprzak, J., Firschke, C., et al. (2005). Assessment of systolic left ventricular function: A multi-centre comparison of cineventriculography, cardiac magnetic resonance imaging, unenhanced and contrast-enhanced echocardiography. European Heart Journal, 26(6), 607-616.

5. Frazin, L., Talano, J. V., Stephanides, L., Loeb, H. S., Kopel, L., \& Gunnar, R. M. (1976). Esophageal echocardiography. Circulation, 54(1), 102-108.

6. Mazic, U., Gavora, P., \& Masura, J. (2001). The role of transesophageal echocardiography in transcatheter closure of secundum atrial septal defects by the Amplatzer septal occluder. American Heart Journal, 142(3), 482-488.

7. Bara, C., Ghodsizad, A., Niehaus, M., Makoui, M., Piechaczek, C., Martin, U., et al. (2006). In vivo echocardiographic imaging of transplanted human adult stem cells in the myocardium labeled with clinically applicable CliniMACS nanoparticles. Journal of the American Society of Echocardiography, 19(5), 563-568.

8. Folland, E. D., Parisi, A. F., Moynihan, P. F., Jones, D. R., Feldman, C. L., \& Tow, D. E. (1979). Assessment of left ventricular ejection fraction and volumes by real-time, twodimensional echocardiography. A comparison of cineangiographic and radionuclide techniques. Circulation, 60(4), 760-766.

9. Thomson, H. L., Basmadjian, A. J., Rainbird, A. J., Razavi, M., Avierinos, J. F., Pellikka, P. A., et al. (2001). Contrast echocardiography improves the accuracy and reproducibility of left ventricular remodeling measurements: a prospective, randomly assigned, blinded study. Journal of the American College of Cardiology, 38(3), 867-875.
10. Hansen, A., Haass, M., Zugck, C., Krueger, C., Unnebrink, K., Zimmermann, R., et al. (2001). Prognostic value of Doppler echocardiographic mitral inflow patterns: implications for risk stratification in patients with chronic congestive heart failure. Journal of the American College of Cardiology, 37(4), 1049-1055.

11. Nagueh, S. F., Middleton, K. J., Kopelen, H. A., Zoghbi, W. A., \& Quinones, M. A. (1997). Doppler tissue imaging: a noninvasive technique for evaluation of left ventricular relaxation and estimation of filling pressures. Journal of the American College of Cardiology, 30(6), 1527-1533.

12. Heimdal, A., Stoylen, A., Torp, H., \& Skjaerpe, T. (1998). Realtime strain rate imaging of the left ventricle by ultrasound. Journal of the American Society of Echocardiography, 11(11), 1013-1019.

13. Leitman, M., Lysyansky, P., Sidenko, S., Shir, V., Peleg, E., Binenbaum, M., et al. (2004). Two-dimensional strain-a novel software for real-time quantitative echocardiographic assessment of myocardial function. Journal of the American Society of Echocardiography, 17(10), 1021-1029.

14. Urheim, S., Edvardsen, T., Torp, H., Angelsen, B., \& Smiseth, O. A. (2000). Myocardial strain by Doppler echocardiography. Validation of a new method to quantify regional myocardial function. Circulation, 102(10), 1158-1164.

15. Edvardsen, T., Urheim, S., Skulstad, H., Steine, K., Ihlen, H., \& Smiseth, O. A. (2002). Quantification of left ventricular systolic function by tissue Doppler echocardiography: Added value of measuring pre- and postejection velocities in ischemic myocardium. Circulation, 105(17), 2071-2077.

16. Bohs, L. N., \& Trahey, G. E. (1991). A novel method for angle independent ultrasonic imaging of blood flow and tissue motion. IEEE Transactions on Bio-Medical Engineering, 38(3), 280-286.

17. Amundsen, B. H., Helle-Valle, T., Edvardsen, T., Torp, H., Crosby, J., Lyseggen, E., et al. (2006). Noninvasive myocardial strain measurement by speckle tracking echocardiography: validation against sonomicrometry and tagged magnetic resonance imaging. Journal of the American College of Cardiology, 47(4), 789-793.

18. Sugeng, L., Weinert, L., Thiele, K., \& Lang, R. M. (2003). Realtime three-dimensional echocardiography using a novel matrix array transducer. Echocardiography (Mount Kisco, NY), 20(7), 623-635.

19. Corsi, C., Lang, R. M., Veronesi, F., Weinert, L., Caiani, E. G., MacEneaney, P., et al. (2005). Volumetric quantification of global and regional left ventricular function from real-time threedimensional echocardiographic images. Circulation, 112(8), 1161-1170.

20. Gutierrez-Chico, J. L., Zamorano, J. L., Perez de Isla, L., Orejas, M., Almeria, C., Rodrigo, J. L., et al. (2005). Comparison of left ventricular volumes and ejection fractions measured by threedimensional echocardiography versus by two-dimensional echocardiography and cardiac magnetic resonance in patients with various cardiomyopathies. The American Journal of Cardiology, 95(6), 809-813.

21. Maehle, J., Bjoernstad, K., Aakhus, S., Torp, H. G., \& Angelsen, B. A. (1994). Three-dimensional echocardiography for quantitative left ventricular wall motion analysis: a method for reconstruction of endocardial surface and evaluation of regional dysfunction. Echocardiography (Mount Kisco, NY), 11 (4), 397-408.

22. Bax, J. J., Abraham, T., Barold, S. S., Breithardt, O. A., Fung, J. W., Garrigue, S., et al. (2005). Cardiac resynchronization therapy: Part 1-issues before device implantation. Journal of the American College of Cardiology, 46(12), 2153-2167.

23. Chung, E. S., Leon, A. R., Tavazzi, L., Sun, J. P., Nihoyannopoulos, P., Merlino, J., et al. (2008). Results of the predictors of response to CRT (PROSPECT) trial. Circulation, 117(20), 26082616. 
24. Chang, S. A., Kim, H. K., Lee, H. Y., Choi, S. Y., Koo, B. K., Kim, Y. J., et al. (2008). Restoration of left ventricular synchronous contraction after acute myocardial infarction by stem cell therapy: New insights into the therapeutic implication of stem cell therapy for acute myocardial infarction. Heart (British Cardiac Society), 94(8), 995-1001.

25. Wei, K., Ragosta, M., Thorpe, J., Coggins, M., Moos, S., \& Kaul, S. (2001). Noninvasive quantification of coronary blood flow reserve in humans using myocardial contrast echocardiography. Circulation, 103(21), 2560-2565.

26. Vogel, R., Indermuhle, A., Reinhardt, J., Meier, P., Siegrist, P. T., Namdar, M., et al. (2005). The quantification of absolute myocardial perfusion in humans by contrast echocardiography: algorithm and validation. Journal of the American College of Cardiology, 45(5), 754-762.

27. Peltier, M., Vancraeynest, D., Pasquet, A., Ay, T., Roelants, V., D'Hondt, A. M., et al. (2004). Assessment of the physiologic significance of coronary disease with dipyridamole real-time myocardial contrast echocardiography. Comparison with technetium-99m sestamibi single-photon emission computed tomography and quantitative coronary angiography. Journal of the American College of Cardiology, 43(2), 257-264.

28. Lafitte, S., Higashiyama, A., Masugata, H., Peters, B., Strachan, M., Kwan, O. L., et al. (2002). Contrast echocardiography can assess risk area and infarct size during coronary occlusion and reperfusion: experimental validation. Journal of the American College of Cardiology, 39(9), 1546-1554.

29. Tsutsui, J. M., Elhendy, A., Anderson, J. R., Xie, F., McGrain, A. C., \& Porter, T. R. (2005). Prognostic value of dobutamine stress myocardial contrast perfusion echocardiography. Circulation, 112 (10), 1444-1450.

30. Schinkel, A. F., Poldermans, D., Elhendy, A., \& Bax, J. J. (2006). Prognostic role of dobutamine stress echocardiography in myocardial viability. Current Opinion in Cardiology, 21(5), 443-449.

31. Janardhanan, R., Moon, J. C., Pennell, D. J., \& Senior, R. (2005). Myocardial contrast echocardiography accurately reflects transmurality of myocardial necrosis and predicts contractile reserve after acute myocardial infarction. American Heart Journal, 149 (2), 355-362.

32. Christiansen, J. P., Leong-Poi, H., Klibanov, A. L., Kaul, S., \& Lindner, J. R. (2002). Noninvasive imaging of myocardial reperfusion injury using leukocyte-targeted contrast echocardiography. Circulation, 105(15), 1764-1767.

33. Kaufmann, B. A., Lewis, C., Xie, A., Mirza-Mohd, A., \& Lindner, J. R. (2007). Detection of recent myocardial ischaemia by molecular imaging of P-selectin with targeted contrast echocardiography. European Heart Journal, 28(16), 2011-2017. 